\title{
CHRONOLOGY OF THE SOLAR SYSTEM'S OLDEST SOLIDS
}

\author{
James N. Connelly, ${ }^{1,2}$ Yuri Amelin, ${ }^{3}$ Alexander N. Krot, ${ }^{4}$ and Martin Bizzarro \\ Received 2008 January 6; accepted 2008 January 28; published 2008 February 19
}

\begin{abstract}
Determining the origins of our solar system and, by proxy, other planetary systems, depends on knowing accurately and precisely the timing and tempo of the transformation of the disk of gas and dust to the solids that formed the planets. Relative ages based on the short-lived nuclide ${ }^{26} \mathrm{Al}$ indicate that high-temperature calciumaluminum inclusions (CAIs) formed before lower temperature chondrules but these ages are heavily dependant on a model of homogeneous distribution of ${ }^{26} \mathrm{Al}$ within the protoplanetary disk. The competing $\mathrm{X}$-wind model argues for heterogeneous distribution of ${ }^{26} \mathrm{Al}$ due to its formation by intra-solar system irradiation such that this system would have no chronological significance. We report a ${ }^{207} \mathrm{~Pb}^{-206} \mathrm{~Pb}$ isochron age of $4565.45 \pm 0.45 \mathrm{Myr}$ for chondrules from the $\mathrm{CV}$ chondrite Allende, an age that is $1.66 \pm 0.48 \mathrm{Myr}$ younger than the accepted $\mathrm{Pb}$ $\mathrm{Pb}$ age for CAIs from this chondrite group. This age offset is in excellent agreement with the relative ages determined using the ${ }^{26} \mathrm{Al}-{ }^{26} \mathrm{Mg}$ system, an observation that supports a supernova origin for ${ }^{26} \mathrm{Al}$ and, importantly, the chronological significance of the ${ }^{26} \mathrm{Al}-{ }^{26} \mathrm{Mg}$ system in general. This is consistent with an early and brief CAIforming event followed by recurrent chondrule formation throughout the life span of the protoplanetary disk. The paucity of old chondrules in chondrite meteorites may reflect their early incorporation into the parent bodies of differentiated meteorites after CAIs were effectively removed from the innermost regions of the protoplanetary disk. Lastly, the agreement between the absolute and relative chronology of CAIs and chondrules requires a solar system age younger than $\sim 4567.5 \mathrm{Myr}$
\end{abstract}

Subject headings: astrochemistry — nuclear reactions, nucleosynthesis, abundances planetary systems: protoplanetary disks — solar system: formation

\section{INTRODUCTION}

Chondrules and calcium-aluminum-rich inclusions (CAIs) are the major components of chondritic meteorites (chondrites) and are among the oldest solids formed in the protoplanetary disk-the disk of dust and gas that surrounded the young Sun. Compositions and textures of CAIs and chondrules indicate that they formed by high-temperature processes that included condensation, evaporation, and, for chondrules and some CAIs, subsequent melting during multiple brief heating episodes possibly induced by shock waves (Scott 2007). Relative timing of CAI and chondrule formation can be established using the short-lived ${ }^{26} \mathrm{Al}$ to ${ }^{26} \mathrm{Mg}$ decay system $\left(t_{1 / 2}=0.73 \mathrm{Myr}\right)$, given that ${ }^{26} \mathrm{Al}$ appears to have been homogeneously distributed in the CAI- and chondrule-forming regions (MacPherson et al. 1995). Based on observations that most CAIs in primitive chondrites formed with an initial ${ }^{26} \mathrm{Al} /{ }^{27} \mathrm{Al}$ ratio of $\sim 6 \times 10^{-5}$ (MacPherson et al. 1995; Bizzarro et al. 2004; Young et al. 2005; Thrane et al. 2006), whereas most chondrules from various chondrite groups formed with ${ }^{26} \mathrm{Al} /{ }^{27} \mathrm{Al}$ ratios of $\leqslant 1.5 \times$ $10^{-5}$ (Kita et al. 2005), it is commonly inferred that CAIs formed at least $1.75 \mathrm{Myr}$ before the majority of chondrules. This chronological interpretation is, however, model dependent: it is based on the critical assumption that ${ }^{26} \mathrm{Al}$ was homogeneously distributed within the early solar system. Homogeneous distribution can be readily achieved if ${ }^{26} \mathrm{Al}$ was produced by stellar nucleosynthesis in a supernova, an asymptotic giant branch star, or a Wolf-Rayet star, and injected into the solar

\footnotetext{
${ }^{1}$ Geological Museum, University of Copenhagen, Øster Voldgade 5-7, DK1350, Denmark.

${ }^{2}$ Jackson School of Geosciences, University of Texas, Austin, Texas; connelly@mail.utexas.edu.

${ }^{3}$ Australian National University, Canberra, Australia.

${ }^{4}$ School of Ocean and Earth Science and Technology, Hawai'i Institute of Geophysics and Planetology, University of Hawai'i at Manoa, Honolulu, Hawai'i.
}

system's parental molecular cloud or, alternatively, into the active protoplanetary disk (Boss 2007). Although recent highprecision $\mathrm{Mg}$ isotope measurements of inner solar system solids, planets, and planetesimals (Bizzarro et al. 2004, 2005; Baker et al. 2005; Thrane et al. 2006) apparently support the homogenous distribution of ${ }^{26} \mathrm{Al}$ and, hence, the chronological significance of the ${ }^{26} \mathrm{Al}-{ }^{26} \mathrm{Mg}$ system, they cannot prove it.

The alternative nonchronological interpretation of ${ }^{26} \mathrm{Al}-{ }^{26} \mathrm{Mg}$ data is based on the X-wind model (Shu et al. 2001; Gounelle et al. 2001) suggesting that CAIs and chondrules formed contemporaneously in isotopically and spatially distinct regions close to the young Sun. The observed difference in their ${ }^{26} \mathrm{Al} /$ ${ }^{27} \mathrm{Al}$ ratios reflects local formation of ${ }^{26} \mathrm{Al}$ by solar-induced energetic particle irradiation such that variations in the initial abundances of ${ }^{26} \mathrm{Al}$ have no direct chronological meaning. The $\mathrm{X}$-wind model was bolstered by the discovery in CAIs of evidence for the former presence of ${ }^{10} \mathrm{Be}$ (McKeegan et al. 2000), an extinct radionuclide uniquely produced by nuclear spallation reactions. Moreover, theoretical calculations are able to qualitatively reproduce the initial abundances of several short-lived radionuclides $\left({ }^{26} \mathrm{Al},{ }^{36} \mathrm{Cl},{ }^{41} \mathrm{Ca}\right.$, and $\left.{ }^{53} \mathrm{Mn}\right)$ reported in meteorites (Gounelle et al. 2001). Distinguishing between these two competing models is of paramount importance, as it provides the basis for understanding the astrophysical setting and chronology of the early solar system, as well as the nature of the CAIand chondrule-forming processes.

In contrast to chronologies based on short-lived isotope chronometers such as the ${ }^{26} \mathrm{Al}-{ }^{26} \mathrm{Mg}$ system, the long-lived $\mathrm{U}-\mathrm{Pb}$ isotope chronology of CAIs and chondrules provides absolute ages that are free from assumptions of parent nuclide homogeneity. Amelin et al. (2002) first reported a resolvable $\mathrm{Pb}-\mathrm{Pb}$ isotopic age difference of $2.5 \pm 1.2 \mathrm{Myr}$ between CAIs from the CV chondrite Efremovka (4567.2 $\pm 0.7 \mathrm{Myr}$, revised to $4567.11 \pm 0.16 \mathrm{Myr}$; Amelin et al. 2006) and chondrules from the CR chondrite Acfer 059 (4564.7 $\pm 0.6 \mathrm{Myr})$. This result, 
TABLE 1

Pb Isotope Data and Model Ages for Allende Chondrules and CAIs

\begin{tabular}{|c|c|c|c|c|c|c|}
\hline Sample & $\begin{array}{l}\text { Weight } \\
(\mathrm{g})\end{array}$ & $\begin{array}{c}\mathrm{U} \\
(\mathrm{ppm})\end{array}$ & $\begin{array}{c}\mathrm{Pb} \\
(\mathrm{ppm})\end{array}$ & ${ }^{204} \mathrm{~Pb} /{ }^{206} \mathrm{~Pb}$ & ${ }^{207} \mathrm{~Pb} /{ }^{206} \mathrm{~Pb}$ & $\begin{array}{l}\text { Model Age } \mathrm{a}^{\mathrm{a}} \\
(\mathrm{Myr})\end{array}$ \\
\hline \multicolumn{7}{|l|}{ Chondrules: } \\
\hline $\mathrm{C} 12-\mathrm{L1}^{\mathrm{b}}$ & $\ldots$ & 0.0552 & 0.5409 & $0.057521(5)$ & $0.87533(11)$ & $4530.9 \pm 1.9$ \\
\hline $\mathrm{C} 12-\mathrm{L} 2^{\mathrm{b}}$ & & 0.0160 & 0.0854 & $0.059455(10)$ & $0.88364(46)$ & $4527.5 \pm 3.1$ \\
\hline C12-L3 & $\ldots$ & 0.0606 & 0.9916 & $0.079094(3)$ & $0.97801(13)$ & $4557.5 \pm 3.4$ \\
\hline C12-L5 & $\ldots$ & 0.0138 & 0.1091 & $0.049692(6)$ & $0.84666(21)$ & $4563.7 \pm 1.8$ \\
\hline C12-L6 & $\ldots$ & 0.0024 & 0.0116 & 0.045895 & $0.82973(117)$ & $4564.2 \pm 6.2$ \\
\hline C12-L7 & $\ldots$ & 0.0239 & 0.1473 & $0.047408(6)$ & $0.83612(16)$ & $4562.5 \pm 1.6$ \\
\hline C12-L8 & $\ldots$ & 0.0367 & 0.0719 & $0.011199(34)$ & $0.67436(139)$ & $4565.2 \pm 1.2$ \\
\hline C12-L9 & $\ldots$ & 0.0759 & 0.1814 & $0.020821(13)$ & $0.71718(61)$ & $4564.2 \pm 1.5$ \\
\hline $\mathrm{C} 12-\mathrm{L} 10^{\mathrm{b}}$ & $\ldots$ & 0.0444 & 0.1729 & $0.029809(24)$ & $0.75116(109)$ & $4543.6 \pm 3.6$ \\
\hline \multicolumn{7}{|l|}{ CAIs: } \\
\hline F2-Plag ${ }^{\mathrm{b}}(<2.85)^{\mathrm{c}}$ & 0.00007 & 0.0013 & 0.0074 & $0.023333(76)$ & $0.71825(313)$ & $4533.6 \pm 1.1$ \\
\hline F2-Mel (2.85-3.15) & 0.00086 & 0.0391 & 0.0998 & $0.001972(8)$ & $0.63350(46)$ & $4566.4 \pm 0.8$ \\
\hline F2-Pyx $(>3.15) \ldots \ldots$ & 0.00052 & 0.0510 & 0.0998 & $0.001972(6)$ & $0.63350(39)$ & $4566.4 \pm 0.8$ \\
\hline TS32-Plag $^{\mathrm{b}}(<2.85) \ldots$ & 0.00035 & 0.0096 & 0.0307 & $0.007118(26)$ & $0.65648(116)$ & $4566.3 \pm 1.6$ \\
\hline TS32-Mel $(2.85-3.15) \ldots$ & 0.00375 & 0.2183 & 0.5683 & $0.000914(2)$ & $0.62934(33)$ & $4567.8 \pm 0.8$ \\
\hline TS32-Рyx $(>3.15) \ldots \ldots$ & 0.00218 & 0.1703 & 0.4757 & $0.002370(2)$ & $0.63549(34)$ & $4566.9 \pm 0.8$ \\
\hline TS33-Plag ${ }^{\mathrm{b}}(<2.85)$ & 0.00017 & 0.0053 & 0.0191 & $0.008387(42)$ & $0.65902(175)$ & $4558.0 \pm 2.0$ \\
\hline TS33-Mel (2.85-3.15) & 0.00138 & 0.0777 & 0.2245 & & & $4566.8 \pm 0.7$ \\
\hline TS33-Pyx (>3.15). & 0.00237 & 0.2107 & 0.6074 & $0.002411(2)$ & $0.63597(36)$ & $4567.6 \pm 0.9$ \\
\hline
\end{tabular}

Notes. - Chondrules were extracted from a single, previously unprocessed $75 \mathrm{~g}$ sample of the CV chondrite Allende. A multichondrule (10) fraction of chondrules were first abraded and then repeatedly precleaned by ultrasonicating in water, ethanol, and acetone prior to a stepwise dissolution procedure using progressively stronger acids (see Connelly \& Bizzarro 2008). Each fraction was spiked with a ${ }^{202} \mathrm{~Pb}-{ }^{205} \mathrm{~Pb}$ tracer prior to $\mathrm{Pb}$ separation using a mixed $\mathrm{HBr}-\mathrm{HNO}_{3}$-based chemistry with $0.055 \mathrm{ml}$ columns filled with anion resin. $\mathrm{Pb}$ was analyzed by thermal ionization mass spectrometry at the University of Oslo using a high-efficiency Si-gel emitter. Allende CAIs F2, TS32, and TS-33 represent various types of CAIs in the currently accepted classification of these objects (Grossman 1980). Pulverized samples of the Allende CAIs were separated using bromoform and methylene iodide into fractions with density of $<2.85,2.85-3.15$, and $>3.15 \mathrm{~g} \mathrm{~cm}^{-3}$, enriched in plagioclase (Plag), melilite (Mel), and pyroxene (Pyx), respectively. These mineral separates were analyzed as part of the same sample batches as Efremovka CAIs and Acfer 059 chondrules following methods outlined in Amelin et al. (2002). Uncertainties are quoted at the $2 \sigma$ level. $\mathrm{Pb}$ isotopic ratios are corrected for blank, spike, and instrumental fractionation.

${ }^{\text {a }}$ Calculated from primordial $\mathrm{Pb}$ (Tatsumoto et al. 1973).

${ }^{\mathrm{b}}$ Not included in isochron age calculations.

${ }^{\mathrm{c}}$ Density range $\left(\mathrm{g} \mathrm{cm}^{-3}\right)$.

however, does not preclude contemporaneous formation of chondrules and CAIs as suggested by the X-wind (Shu et al. 2001; Gounelle et al. 2001), since CAIs and chondrules analyzed by Amelin et al. (2002) are from two different chondrite groups. Taking advantage of improved methods for isotopic analysis of small quantities of $\mathrm{Pb}$ by thermal ionization mass spectrometry (Table 1) and relatively large sizes of CAIs ( 5$10 \mathrm{~mm})$ and chondrules $(\sim 1 \mathrm{~mm})$ in CV chondrites, we have investigated the absolute chronology of chondrules and CAIs from this chondrite group to test the X-wind model of CAI and chondrule formation and to constrain the origin of ${ }^{26} \mathrm{Al}$. The small sizes and rare occurrence of CAIs in other carbonaceous, ordinary, and enstatite chondrite groups preclude high-precision $\mathrm{Pb}-\mathrm{Pb}$ isotopic age dating of chondrules and CAIs in any other single chondrite group.

\section{RESULTS}

We extracted a single fraction of multiple uncrushed chondrules and subjected it to a progressive dissolution procedure. Six dissolution steps (Table 1) yielded widely spaced colinear points in ${ }^{204} \mathrm{~Pb} /{ }^{206} \mathrm{~Pb}$ versus ${ }^{207} \mathrm{~Pb} /{ }^{206} \mathrm{~Pb}$ space (Fig. $1 a$ ). These data were combined with highly radiogenic $\mathrm{Pb}$ analyses from the residual portions of 15 lightly crushed and aggressively leached fractions (14 multichondrule and one single chondrule; Amelin \& Krot 2007). Combining the two $\mathrm{Pb}-\mathrm{Pb}$ data sets for chondrules from Allende provides an integrated linear data array that corresponds to a $\mathrm{Pb}-\mathrm{Pb}$ isochron age of $4565.45 \pm$
$0.45 \mathrm{Myr}$ (Fig. 1a). The robustness of this age is reinforced by the extrapolation of the isochron through the accepted estimate of the solar system primordial $\mathrm{Pb}$ isotopic composition (PAT; Tatsumoto et al. 1973) that indicates a two-component system of initial and radiogenic $\mathrm{Pb}$. Three CAIs from Allende were crushed, density separated into three subfractions and acid washed prior to analyses. The residues of the two densest subfractions, composed mainly of melilite and pyroxene, from all three CAIs define a single line corresponding to $\mathrm{a} \mathrm{Pb}-\mathrm{Pb}$ isochron age of $4567.72 \pm 0.93 \mathrm{Myr}$ (Fig. 1b), with the error envelope of the line embracing PAT.

\section{DISCUSSION}

The resolved older age for Allende CAIs rules out the possibility that the younger age obtained for chondrules from this same meteorite reflects resetting of the $\mathrm{Pb}$ isotopic system by diffusion during fluid-assisted thermal metamorphism on the $\mathrm{CV}$ parent body. Instead, the $\mathrm{Pb}-\mathrm{Pb}$ isochron age for Allende chondrules of $4565.45 \pm 0.45 \mathrm{Myr}$ represents the average age of the last crystallization event that affected the chondrules analyzed in these fractions. Citing linearity of residues and stepwise dissolution steps and colinearity of one single chondrule fraction, we infer a sharp peak in the distribution of ages around this average age. The Allende CAI age of $4567.72 \pm$ $0.93 \mathrm{Myr}$ overlaps the more precise age of CAIs from Efremovka (Amelin et al. 2002, 2006), indicating that CAIs in Allende are not significantly younger than those in Efremovka. 

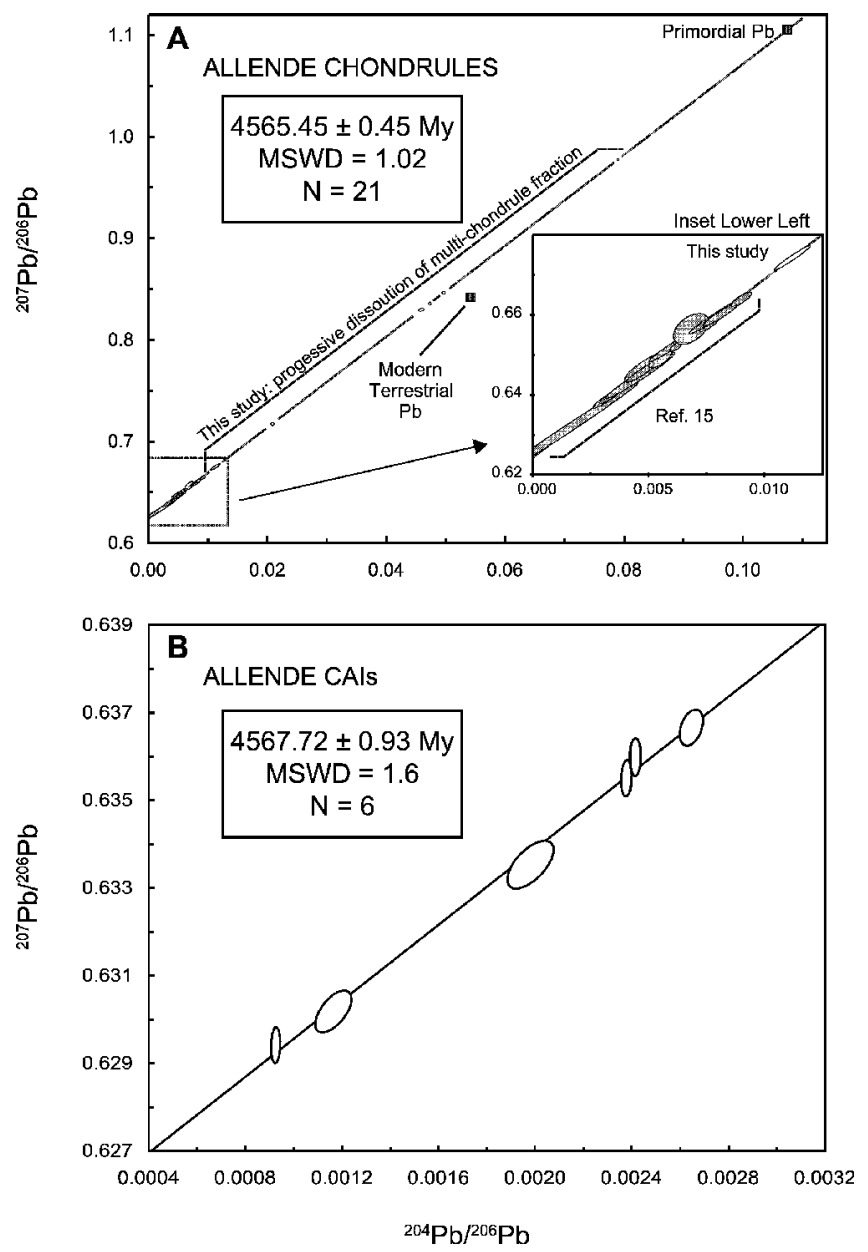

FIG. 1.—Pb-Pb isochron diagrams. Error ellipses are $2 \sigma$. Isochron age errors are $95 \%$ confidence intervals. MSWD $=$ Mean square of weighted deviations. $N=$ number of analyses. (a) Allende chondrules. (b) Allende CAIs.

Using the more precise Efremovka CAI age, our age for chondrules defines an offset of $1.66 \pm 0.48 \mathrm{Myr}$ between the formation of CAIs and chondrules in CV chondrites.

A direct comparison of $\mathrm{Pb}-\mathrm{Pb}$ and ${ }^{26} \mathrm{Al}-{ }^{26} \mathrm{Mg}$ ages of Allende and Efremovka chondrules can be complicated by disturbances of some internal ${ }^{26} \mathrm{Al}-{ }^{26} \mathrm{Mg}$ isochrons during late-stage, thermal metamorphism on the CV parent body (LaTourette \& Wasserburg 1998). Indeed, the ${ }^{26} \mathrm{Al} /{ }^{27} \mathrm{Al}$ ratios in chondrules from $\mathrm{CV}$ chondrites, inferred from ${ }^{26} \mathrm{Mg}$ excesses determined by ion microprobe, range from $1.2 \times 10^{-5}$ to $0.3 \times 10^{-5}$ (Hutcheon et al. 2000). Whereas the lowest ${ }^{26} \mathrm{Al} /{ }^{27} \mathrm{Al}$ ratios probably reflect isotopic disturbances during fluid-assisted parent-body metamorphism, we infer that the plateau of ${ }^{26} \mathrm{Al} /{ }^{27} \mathrm{Al}$ ratios (corresponding ages of $\sim 1.7 \mathrm{Myr}$ after CAIs) records the time of the last crystallization of chondrules. This is strongly supported by the well-defined $\sim 2 \mathrm{Myr}$ offset between ages inferred from internal ${ }^{26} \mathrm{Al}-{ }^{26} \mathrm{Mg}$ isochrons for chondrules and CAIs from Ningqiang - the least metamorphosed CV-like chondrite studied to date (Hsu et al. 2003). This consistency of ages for CV chondrules inferred from internal ${ }^{26} \mathrm{Al}-{ }^{26} \mathrm{Mg}$ isochrons and our $\mathrm{Pb}-\mathrm{Pb}$ age validates the ${ }^{26} \mathrm{Al}-{ }^{26} \mathrm{Mg}$ method as a chronometer when applied to appropriate samples and, therefore, the underlying assumption of ${ }^{26} \mathrm{Al}$ homogeneity in the early solar system.

$\mathrm{The} \mathrm{Pb}-\mathrm{Pb}$ age offset between chondrules and CAIs from the same chondrite group-and hence the chronological significance of the ${ }^{26} \mathrm{Al}-{ }^{26} \mathrm{Mg}$ system-is inconsistent with the Xwind model for the origin of chondrules and CAIs, and production of ${ }^{26} \mathrm{Al}$ by solar-induced ${ }^{3} \mathrm{He}$ irradiation (Shu et al. 2001; Gounelle et al. 2001). Instead, our results support a stellar origin for ${ }^{26} \mathrm{Al}$ followed by injection into the nascent solar system from stellar winds or supernova debris, requiring that our Sun formed in association with one or numerous massive stars. This conclusion is in agreement with the discovery of traces of ${ }^{60} \mathrm{Fe}$ in chondrite components (Tachibana \& Huss 2003) at the level that can only be produced in massive stars and, therefore, strengthens the proposal that our solar system formed in a stellar cluster, perhaps analogous to star-forming regions such as the Orion or Eagle nebulas (Hester \& Desch 2005; Bizzarro et al. 2007). However, this does not preclude formation of some short-lived radionuclides such as ${ }^{10} \mathrm{Be}$ and ${ }^{53} \mathrm{Mn}$ by proton-irradiation reactions near the young Sun, given that the ${ }^{3} \mathrm{He}$ and proton irradiation originate in different solar flare events that may be decoupled. An insignificant amount of ${ }^{3} \mathrm{He}$ irradiation in the early solar system is consistent with the low inferred meteoritic abundance of ${ }^{41} \mathrm{Ca}-$ a nuclide efficiently produced by ${ }^{3} \mathrm{He}$ irradiation-compared to that predicted by models attempting to invoke an irradiation origin for ${ }^{26} \mathrm{Al}$ (Gounelle et al. 2001).

The $\mathrm{Pb}-\mathrm{Pb}$ ages of CAIs from $\mathrm{CV}$ chondrites (4567.11 \pm $0.16 \mathrm{Myr}$; Amelin et al. 2006) is consistent with an early and brief duration of CAI formation ( $\$ 100,000 \mathrm{yr}$ ), perhaps during the infall stage of the protostellar evolution of the Sun (Bizzarro et al. 2004; Thrane et al. 2006). In contrast, the ages of chondrules from CV (4565.45 $\pm 0.45 \mathrm{Myr}), \mathrm{CR}$ (4564.1-4564.7 Myr; Amelin et al. 2002), and CB (4562.7 $\pm 0.5 \mathrm{Myr}$; Krot et al. 2005) chondrites suggest a more protracted and/or longer period of chondrule formation within the protoplanetary disk, possibly related to shock wave heating (Scott 2007) and collisions between planetary embryos (Krot et al. 2005). Two lines of evidence, however, suggest that the short duration of chondrule formation as recorded by the Allende meteorite may not reflect primary chondrule formation in the young solar system. First, a high-precision ${ }^{26} \mathrm{Al}-{ }^{26} \mathrm{Mg}$ age inferred from an internal isochron relationship in one Allende chondrule suggests that chondrule formation may have started within $\sim 200,000 \mathrm{yr}$ of CAI formation (Bizzarro et al. 2004). Second, a reassessment of the $\mathrm{Pb}-\mathrm{Pb}$ age of $\mathrm{CR}$ chondrules from Acfer 059 obtained from a PAT model age using the two most radiogenic chondrules of Amelin et al. (2002) suggests that they may have formed as late as $4564.1 \pm 0.6 \mathrm{Myr}$, that is, significantly younger than the $\mathrm{Pb}-\mathrm{Pb}$ age of Allende chondrules. This younger age is in better agreement with the ${ }^{26} \mathrm{Al}-{ }^{26} \mathrm{Mg}$ ages of CR chondrules (Nagashima et al. 2007), as well as a tentative younger accretion age of the CR parent body that could be implied by lower peak metamorphic temperatures compared to that of the CV chondrite parent body (Scott 2007), assuming that ${ }^{26} \mathrm{Al}$ was an important heat source for planetesimal differentiation (Bizzarro et al. 2005; Baker et al. 2005). These observations collectively suggest that chondrule formation may have been a punctuated, recurrent process active during the entire life span of the protoplanetary disk, thereby providing an efficient mechanism for continuous thermal processing of primordial dust and early formed solar system solids. The paucity of old chondrules in chondrite meteorites may, in turn, reflect their early incorporation into the parent bodies of differentiated meteorites, given that the accretion of differentiated planetesimals is commonly believed to have predated that of chondrite parent bodies 
(Bizzarro et al. 2005; Baker et al. 2005; Kleine et al. 2005). Furthermore, the confirmation of a significant age difference between CAIs and chondrules from the same chondrite group infers that CAIs were removed from the innermost regions of the protoplanetary disk soon after their formation to avoid thermal reprocessing and isotopic resetting during the chondruleforming period.

Finally, the chronological significance of the ${ }^{26} \mathrm{Al}-{ }^{26} \mathrm{Mg}$ clock allows us to place strong constraints on the maximum age of the solar system. Based on short- and long-lived radioisotope chronometers, a number of studies have recently proposed an upward revision of the age of the solar system with estimates ranging from $\sim 4568$ to $\sim 4571 \mathrm{Myr}$ (Lugmair \& Shukolyukov 1998; Nyquist et al. 2003; Baker et al. 2005; Bouvier et al.
2007; Burkhardt et al. 2007). However, this is inconsistent with the agreement between the ${ }^{26} \mathrm{Al}-{ }^{26} \mathrm{Mg}$ and $\mathrm{Pb}-\mathrm{Pb}$ systems indicating a $\sim 2$ to $\sim 3 \mathrm{Myr}$ age difference between CAIs and chondrules from $\mathrm{CV}$ and $\mathrm{CR}$ chondrites, respectively, defining a maximum solar system age of $\sim 4567.5 \mathrm{Myr}$. We reiterate that the currently most precise and accurate estimate of the timing of primary CAI formation-and consequently the age of the solar system-is that defined by the E60 Efremovka CAI at 4567.11 \pm 0.16 Myr (Amelin et al. 2002, 2006).

Financial support for this project was provided by the Danish National Science Foundation, the Carlsberg Foundation, and the Jackson School of Geosciences.

\section{REFERENCES}

Amelin, Y., \& Krot, A. N. 2007, Meteoritics Planet. Sci., 42, 1321

Amelin, Y., Krot, A. N., Hutcheon, I. D., \& Ulyanov, A. A. 2002, Science, 297, 1678

Amelin, Y., Wadhwa, M., \& Lugmair, G. 2006, Lunar Planet. Sci. Conf., 37, 1970

Baker, J., Bizzarro, M., Wittig, N., Connelly, J., \& Haack, H. 2005, Nature, 436, 1127

Bizzarro, M., Baker, J. A., \& Haack, H. 2004, Nature, 431, 275

Bizzarro, M., Baker, J. A., Haack, H., \& Lundgaard, K. L. 2005, ApJ, 632, L41

Bizzarro, M., et al. 2007, Science, 316, 1178

Boss, A. P. 2007, ApJ, 660, 1707

Bouvier, A., Blichert-Toft, J., Moynier, F., Vervoort, J. D., \& Albarède, F. 2007, Geochim. Cosmochim. Acta, 71, 1583

Burkhardt, C., et al. 2007, Meteoritics Planet. Sci., 42, 5189

Connelly, J. N., \& Bizzarro, M. 2008, Chemical Geology, submitted

Gounelle, M., et al. 2001, ApJ, 548, 1051

Grossman, L. 1980, Annu. Rev. Earth Planet. Sci., 8, 559

Hester, J. J., \& Desch, S. J. 2005, in Chondrites and the Protoplanetary Disk, ed. A. N. Krot et al. (San Francisco: ASP), 107

Hsu, W., Huss, G. R., \& Wasserburg, G. J. 2003, Meteoritics Planet. Sci., 38, 35
Hutcheon, I. D., Krot, A. N., \& Ulyanov, A. A. 2000, Lunar Planet. Sci. Conf., 31, 1869

Kita, N., et al. 2005, in Chondrites and the Protoplanetary Disk, ed. A. N. Krot et al. (San Francisco: ASP), 558

Kleine, T., Mezger, K., Palme, H., Scherer, E., \& Münker, C. 2005, Geochim. Cosmochim. Acta, 69, 5805

Krot, A. N., Amelin, Y., Cassen, P., \& Meibom, A. 2005, Nature, 436, 989

LaTourrette, T., \& Wasserburg, G. J. 1998, Earth Planet. Sci. Lett., 158, 91

Lugmair, G. W., \& Shukolyukov, A. 1998, Geochim. Cosmochim. Acta, 62, 2863

MacPherson, G. J., Davis, A. M., \& Zinner, E. K. 1995, Meteoritics, 30, 365

McKeegan, K., Chaussidon, M., \& Robert, F. 2000, Science, 289, 1334

Nagashima, K., Krot, A. N., \& Chaussidon, M. 2007, Meteoritics Planet. Sci., 42,5291

Nyquist, L. E., Reese, Y., Wiesmann, H., Shih, C.-Y., \& Takeda, H. 2003, Earth Planet. Sci. Lett., 214, 11

Scott, E. R. D. 2007, Annu. Rev. Earth Planet. Sci., 35, 577

Shu, F. H., Shang, H., Gounelle, M., Glassgold, A. E., \& Lee, T. 2001, ApJ, 548,1029

Tachibana, S., \& Huss, G. R. 2003, ApJ, 588, L41

Tatsumoto, M., Knight, R. J., \& Allègre, C. J. 1973, Science, 180, 1279

Thrane, K., Bizzarro, M., \& Baker, J. A. 2006, ApJ, 646, L159

Young, E. D., et al. 2005, Science, 308, 223 